\title{
Síndrome del cascanueces anterior y posterior acompañado de vena renal izquierda circumaórtica en un adolescente. A propósito de un caso

\author{
Anterior and posterior nutcracker syndrome accompanying left circumaortic \\ renal vein in an adolescent. Case report
}

Dr. Mehmet B. Özkan ${ }^{a}$, Dra. Meltem Ceyhan Bilgicia y Dr. Emre Hayalioglu

\section{RESUMEN}

La vena renal izquierda (VRI) presenta diversas variantes en su desarrollo; las dos más frecuentes son la circumaórtica y la retroaórtica. El síndrome del cascanueces anterior es la compresión de la VRI entre la aorta y la arteria mesentérica superior, mientras que el síndrome del cascanueces posterior se produce entre la columna vertebral y la aorta. Derivaron a un varón adolescente (16 años de edad) a la sala de emergencias debido a dolor en una de las fosas renales. En la tomografía computada sehallóla combinación de síndromedel cascanueces anterior y posterior en la vena renal izquierda circumaórtica, circunstancia nunca antes descrita en un adolescente.

Palabras clave: vena renal circumaórtica, síndrome del cascanueces anterior y posterior, adolescente, pediatría, radiología.

http:/ /dx.doi.org/10.5546/aap.2016.e114

\section{INTRODUCCIÓN}

La anatomía de la vena renal izquierda (VRI) es de una compleja embriogénesis. Las anomalías venosas del desarrollo incluyen las variantes circumaórtica o retroaórtica. ${ }^{1}$ El síndrome del cascanueces anterior se define como la compresión de la VRI entre la arteria mesentérica superior (AMS) y la aorta, mientras que el síndrome del cascanueces posterior es el término utilizado para referirse a la compresión de la VRI retroaórtica entre la aorta y la columna vertebral. ${ }^{2}$ Es sumamente raro que la VRI circumaórtica acompañe el síndrome del cascanueces anterior y posterior; en las publicaciones científicas se ha notificado solamente una vez en una mujer de mediana edad. ${ }^{3}$ En este artículo describimos esta característica en un adolescente y realizamos una breve revisión de las publicaciones.

a. Departamento de Radiología Pediátrica.

19 Mayıs Üniversitesi, Kurupelit Kampüsü, Samsun, Turquía.

Correspondencia:

Dr. Mehmet B. Özkan: Burakozkan79@hotmail.com

Financiamiento: ninguno.

Conflicto de intereses: ninguno que declarar.

Recibido: 11-08-2015

Aceptado: 19-10-2015

\section{A propósito de un caso}

Un varón adolescente de 16 años arribó a la sala de emergencias con dolor en la fosa renal izquierda y dolor a la palpación. El dolor en la fosa renal era intermitente. El paciente informó que había tenido dolor dos o tres veces en el mes. El dolor no tenía una característica específica, como un cólico, ni una variante típica de un órgano. El dolor se localizaba en la región superior izquierda. La presión arterial del paciente era 125/84 $\mathrm{mmHg}$, lo que denota valores levemente altos de hipertensión. Sin embargo, no tenía fiebre, hematuria, vómitos ni diarrea; tampoco tenía antecedentes de traumatismo. En el análisis de orina, los valores estaban dentro de los límites normales, la depuración de creatinina era de $98 \mathrm{ml} / \mathrm{min}$. El peso y la estatura del paciente estaban dentro de los parámetros porcentuales normales.

Anteriormente, le habían diagnosticado poliserositis familiar recurrente (familial Mediterranean fever, FMF). Para descartar la FMF, se le realizó una ecografía, que no reveló problemas específicos. No se observaron líquido libre ni afectación de las vísceras macizas. La ausencia de líquido libre en los espacios peritoneales descartaba un episodio de FMF. Se le realizó una tomografía computada (TC), donde se observó que la VRI circumaórtica drenaba en la vena cava inferior. La VRI se dividía en el trayecto, cerca de la aorta descendente. La rama superior anterior estaba comprimida entre la AMS y la aorta. Además, la rama inferior posterior estaba comprimida entre la aorta y la columna vertebral. Debido a la compresión, se produjo dilatación bulbosa (Figura 1a,b).

El paciente no tenía hematuria; y la resolución espontánea del dolor en dos días descartó la necesidad de un tratamiento quirúrgico. Un año y medio después, el paciente no tenía dolor ni episodios intermitentes. En este período, el control de la hipertensión indicó un valor de $132 / 70 \mathrm{mmHg}$, que es aún un tanto elevado. 


\section{DISCUSIÓN}

La VRI fetal se desarrolla entre la cuarta y la octava semana de gestación. La secuencia del desarrollo está repleta de distintos mecanismos complejos, que incluyen movimientos de regresión y rotación. Durante este proceso, el desarrollo inadecuado produce variantes en el sistema venoso renal. El fallo en la regresión de la anastomosis del arco posterior produce VRI circumaórtica. ${ }^{4}$ Las dos variantes más frecuentes de VRI son los tipos circumaórtico y retroaórtico. La incidencia mediana de VRI circumaórtica observada en cadáveres es del 7,0\%, mientras que las variantes observadas mediante imágenes de diagnóstico representan el 1-3\%. ${ }^{5}$

En los adultos, la TC con contraste es el método preferido para identificar variantes de la vena renal, aunque implica la exposición a una dosis de radiación. ${ }^{4}$ Sin embargo, no existe información clara acerca de las variantes de la vena renal en niños.

La mayoría de los casos individuales se hallan casualmente. Es importante tener conocimiento de estas variantes antes de realizar un procedimiento quirúrgico, lo que podría derivar en una hemorragia de la vena dorsal. ${ }^{6}$ De Schepper describió la compresión de la VRI entre la AMS y la aorta como síndrome del cascanueces anterior. La compresión análoga posterior entre la AMS y la columna vertebral se denomina síndrome del cascanueces posterior. El término "síndrome del cascanueces posterior" se refiere a la hipertensión de la vena renal izquierda secundaria a la compresión de la vena renal izquierda retroaórtica, que cruza entre la aorta y la columna vertebral. ${ }^{3}$ Los osteófitos vertebrales también pueden causar síndrome del cascanueces posterior, según lo definido por Rassi y col. ${ }^{7}$

El criterio diagnóstico del síndrome del cascanueces anterior es el tamaño del ángulo entre la aorta y la AMS, el cual se ha notificado con un valor de $39,3^{\circ} \pm 4,3^{\circ}$, aunque ciertamente, en su punto más bajo, puede alcanzar aproximadamente $14,5^{\circ}{ }^{8}$ La medición en los niños ha sido de $17^{\circ}$ $57^{\circ}$, más estrecho que en el grupo de niños sanos, pero no existe un criterio de ángulo definido para el síndrome del cascanueces posterior.

El método de referencia para diagnosticar el síndrome del cascanueces es la flebografía retrógrada y cine-videoangiografía con determinación del gradiente de presión reno-cava.

La cine-videoangiografía con visualización muestra el punto exacto de compresión de la VRI en el cruce mesoaórtico y el reflujo del contraste retrógrado hacia las venas suprarrenal y gonadal. ${ }^{8}$

El síndrome del cascanueces anterior y posterior causa hipertensión venosa y la presencia de colaterales venosas intra- y extrarrenales, que podrían causar várices pélvicas y síndrome de congestión.

El aumento de la presión intrarrenal debido a la compresión a nivel mesoaórtico produce reflujo hacia las venas ováricas o testiculares izquierdas. Este reflujo causa varicocele en la

FIGURA 1. Reconstrucción de imágenes de proyección de máxima intensidad a partir de imágenes de TC que muestra: a- la rama superior anterior comprimida entre la arteria mesentérica superior y la aorta (punta de flecha),

b- la rama inferior posterior comprimida entre la aorta y la columna vertebral (flecha).

En ambas se observa dilatación bulbosa segmentaria debido a la compresión
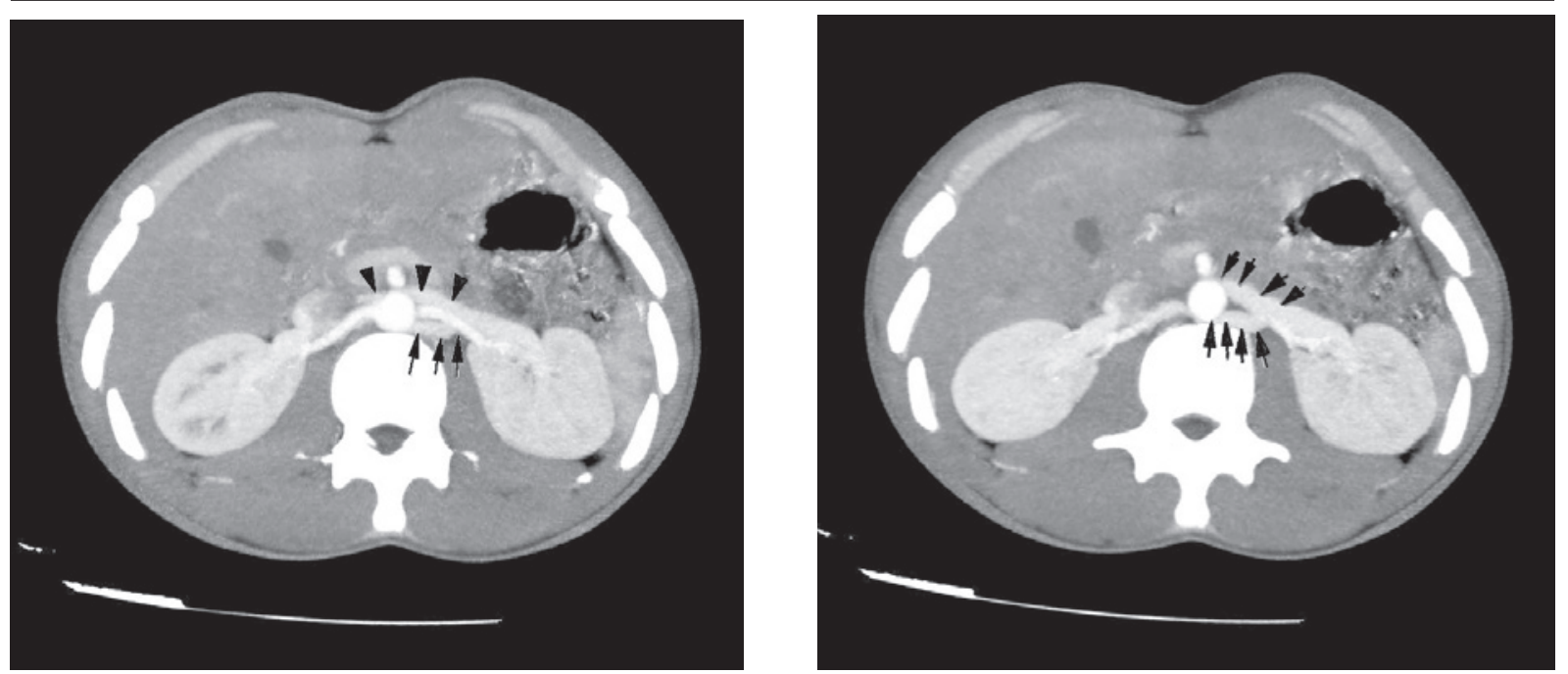
región testicular. En la bibliografía no se halló correlación con una edad específica. Por lo tanto, en nuestro caso, el aumento de la presión de la vena renal izquierda no fue suficiente para causar circulación colateral o un varicocele en la región testicular. Esto podría deberse a la edad de nuestro paciente.

La hematuria es otro signo frecuente cuando existe dolor intenso en la fosa renal izquierda. Alaygut y col., ${ }^{9}$ demostraron que la proteinuria es el síntoma más frecuente que acompaña la hematuria en los niños.

Se han descrito diversos métodos para el tratamiento del síndrome del cascanueces; la primera línea de tratamiento en los adultos es el tratamiento intravascular. ${ }^{10}$ En el grupo de edad pediátrica, se ha descrito la transposición de la VRI como un novedoso procedimiento quirúrgico. ${ }^{11}$ Nuestro paciente no tenía hematuria ni varicocele. Se quejaba de dolor intermitente. Se observó dilatación de los componentes anteriores y posteriores de la vena renal. Los pacientes sometidos a cirugía o a un tratamiento intervencionista tenían hematuria o síndrome de congestión pélvica. ${ }^{8-11} \mathrm{La}$ asociación del síndrome del cascanueces anterior y posterior con la VRI circumaórtica se ha descrito solamente una vez en las publicaciones científicas en inglés, en una mujer de mediana edad. ${ }^{3}$

Hasta donde sabemos, este es el primer caso descrito en la bibliografía en un paciente adolescente.

\section{CONCLUSIÓN}

A modo de conclusión, en el diagnóstico diferencial del dolor en la fosa renal izquierda con hematuria deben tenerse en cuenta las variantes de la VRI. El radiólogo debe informar con precisión la anatomía venosa, ya que podría explicar la causa del dolor, sin necesidad de realizar otras pruebas diagnósticas.

\section{REFERENCIAS}

1. Yi SQ, Ueno Y, Naito M, Ozaki N, et al. The three most common variations of the left renal vein: a review and meta-analysis. Surg Radiol Anat 2012;34(9):799-804.

2. Ali-El-Dein B, Osman Y, Shehab El-Din AB, El-Diasty T, et a. Anterior and posterior nutcracker syndrome: a report on 11 cases. Transplant Proc 2003;35(02):851-3.

3. De Visschere P, De Man R, Rosseel F, Crolla D, et al. Combined anterior and posterior nutcracker phenomenon in circumaortic left renal vein [Internet]. Vienna: EuroRad; 2008 Nov 12. [Acceso el: 22 de octubre de 2015]. Disponible en: http:/ / www.eurorad.org/case.php?id=6962

4. Dilli A, Ayaz UY, Kaplano lu H, Saltas H, et al. Evaluation of the left renal vein variations and inferior vena cava variations by means of helical computed tomography. Clin Imaging 2013;37(3):530-5.

5. Zhu J, Zhang L, Yang Z, Zhou H, et al. Classification of the renal vein variations: a study with multidetector computed tomography. Surg Radiol Anat 2015;37(6):667-75.

6. Resorlu M, Sariyildirim A, Resorlu B, Sancak EB, et al. Association of congenital left renal vein anomalies and unexplained hematuria: multidetector computed tomography findings. Urol Int 2015;94(2):177-80.

7. Rassi I, Khabbaz Z, Chelala D, Jebara VA. A new variant of the posterior nutcracker phenomenon. J Vasc Surg 2010;51(5):1279.

8. Inal M,Karadeniz Bilgili MY, SahinS. Nutcracker syndrome accompanying pelvic congestion syndrome; color doppler sonography and multislice CT findings: a case report. Iran J Radiol 2014;11(2):e11075.

9. Alaygut D, Bayram M, Soylu A, Cakmakcı H, et al. Clinical course of children with nutcracker syndrome. Urology 2013;82(3):686-90.

10. Liu Y, Sun Y, Wu XJ, Jiang Y, et al. Endovascular stent placement for the treatment of nutcracker syndrome. Int Urol Nephrol 2012;44(4):1097-100.

11. Reed NR, Kalra M, Bower TC, Vrtiska TJ, et al. Left renal vein transposition for nutcracker syndrome. J Vasc Surg 2009;49(2):386-93. 